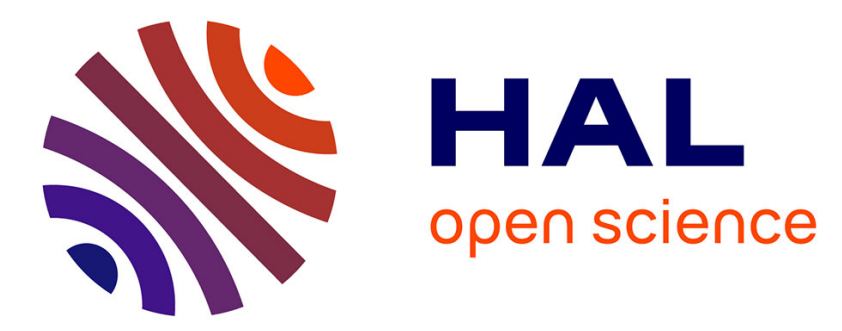

\title{
Physical fitness levels of adolescents in the Ile de France region: comparisons with European standards and relevance for future cardiovascular risk
}

Jeremy Vanhelst, S Fardy Paul, Didier Chapelot, Gregory Czaplicki, Zekya Ulmer

\section{To cite this version:}

Jeremy Vanhelst, S Fardy Paul, Didier Chapelot, Gregory Czaplicki, Zekya Ulmer. Physical fitness levels of adolescents in the Ile de France region: comparisons with European standards and relevance for future cardiovascular risk. Clinical Physiology and Functional Imaging, 2016, Clinical physiology and functional imaging, 36, pp.476-481. 10.1111/cpf.12253 . hal-02177237

\section{HAL Id: hal-02177237 \\ https://hal.univ-lille.fr/hal-02177237}

Submitted on 17 Jul 2019

HAL is a multi-disciplinary open access archive for the deposit and dissemination of scientific research documents, whether they are published or not. The documents may come from teaching and research institutions in France or abroad, or from public or private research centers.
L'archive ouverte pluridisciplinaire HAL, est destinée au dépôt et à la diffusion de documents scientifiques de niveau recherche, publiés ou non, émanant des établissements d'enseignement et de recherche français ou étrangers, des laboratoires publics ou privés. 
Physical fitness levels of adolescents in the Ile de France region: comparisons with Europeans standards and relevance for future cardiovascular risk
Jérémy Vanhelst ${ }^{1-2}$, Paul S Fardy ${ }^{3}$, Didier Chapelot ${ }^{4}$, Grégory Czaplicki ${ }^{5,}$ Zekya Ulmer $^{6}$

\footnotetext{
${ }^{1}$ Inserm U995, Université Lille Nord de France, Lille, France

${ }^{2}$ CIC-PT-1403-Inserm-CH\&U, Lille, France

${ }^{3}$ Professor Emeritus, Queens College, City University of New York, Flushing, NY

${ }^{4}$ Paris 13 University, Sorbonne Paris Cité, Nutritional Epidemiology Research Unit, Bobigny, France

${ }^{5}$ Mutualité Française, Ile de France, Paris, France

${ }^{6}$ Fédération Nationale Mutualité Française, Paris, France
}

Corresponding author information: J. Vanhelst

Antenne pédiatrique du CIC

Hôpital Jeanne de Flandre

CHRU de Lille

Avenue Eugène Avinée

59000 Lille Cedex

Tel: +33 320446058

Fax: +33 320446687

E-mail: jeremy.vanhelst@ chru-lille.fr

Short title: Physical fitness in French youth 


\begin{abstract}
The aim was to assess physical fitness in French schoolchildren in the region of Ile de France and to compare the results with European countries. The relationship between physical fitness and future health profile was of particular interest. Participants were 1851 French youth in the Ile-de-France region. Cardiorespiratory fitness, muscular endurance, speed, flexibility and speed agility were tested. Independent t-tests were used to compare differences between different variables. Spearman's rho correlation coefficients assessed the relationship between Body Mass Index, socioeconomic status and physical fitness. Boys were physically fitter than girls with the most significant difference being in agility. Subjects of normal weight have significantly better results than overweight or obese adolescents $(+10.9$ to $56.1 \%)(\mathrm{p}<0.05)$. Subjects with high socio economic status had better physical fitness than those with low socioeconomic status $(+0.5$ to $9.4 \%)(\mathrm{p}<0.05)$. Results also showed that the percentage of adolescents at increased future cardiovascular risk was 15.3 and $10.2 \%$ for boys and girls, respectively. Physical fitness in French schoolchildren living in the region of Ile de France is relatively low and unfavourable, especially in girls, when compared with existing European test results. In contrast, the adolescents' boys are generally fitter and also above the average of the European data. Introducing a health promotion curriculum in the schools of Ile de France is suggested to improve health and physical fitness.
\end{abstract}

Keywords: Assessment, Youth, Aerobic fitness, Muscular strength, Speed, Flexibility, Health 


\section{Introduction}

Physical fitness is an important determinant of health in children and adolescents (Ortega et al., 2008). Health-related physical fitness includes muscular strength, flexibility, speed/agility, and cardiorespiratory fitness (Heyward, 1991). Physically fit children and adolescents have fewer mental, nutritional, gastroenterological, cardiac, and respiratory diseases (Ortega et al., 2008). Poor physical fitness is a strong risk factor for cardiovascular disease, even more powerful than dyslipidemia, hypertension or obesity (Myers et al., 2002).

Cardiorespiratory fitness is the most significant health-related fitness measure in youth and has been well studied in European, American, African, Asian and Australian adolescents (Heyward, 1991; Olds et al., 2006; Ortega et al., 2011). Olds et al. (2006) reported on more than 100 studies of cardiorespiratory fitness in children and adolescents in 37 countries. However, other components of physical fitness are related to bone health, cardiovascular diseases, chronic musculoskeletal injuries and back problems in youth (Sjolie, 2004; Vicente-Rodriguez et al., 2004; Vicente-Rodriguez et al., 2008; Gale et al., 2007; Malina et al., 2004; Ruiz et al., 2009). Improvement in muscular strength from childhood to adolescence was negatively associated with changes in adiposity, a predictor of improved cardiovascular profile later in life (Ruiz et al., 2009).

The main objective of this study was to measure physical fitness levels in a large sample of French schoolchildren in the region of Ile de France and to compare the findings to other European countries. Cardiorespiratory fitness, as an important risk factor for cardiovascular disease, was of particular interest.

\section{Methods}




\section{Study design}

The current study was based on data from the French health promotion program "Move... A priority for your health" (http://www.bougetasante.fr/). The main aim of this program was to promote the benefits of physical activity and physical fitness on the health of French youth, ages 11 to 15 years. Data were collected between 2009 and 2013 in the Ile de France region (Paris Suburban, France). The program has been adopted in 23 schools throughout the region. The study was approved by the Research Ethical Committee (CPP Nord-Ouest IV, Lille, France). All procedures were performed in accordance with the ethical standards of the Helsinki Declaration of 1975 as revised in 2008 and the European Good Clinical Practices and with the ethical standards of the sport and exercise science research (Béghin et al., 2008; Harriss \& Atkinson, 2011).

A manual of operations was developed for the physical education teachers and study subjects in order to match tests across schools and improve homogeneity. Included in the manual was: rationale of the study, procedures of tests, and how data were recorded.

\section{Measurements}

\section{Physical Measures}

Height and weight were measured by a school nurse. Weight was measured in shorts and $\mathrm{T}$ shirts without shoes to the nearest $0.1 \mathrm{~kg}$ using an electronic scale. Height was measured without shoes to the nearest $0.1 \mathrm{~cm}$ using a standard physician's scale. The body mass index (BMI) of the subjects was calculated from their measured height and weight $\left(\mathrm{BMI}=\right.$ weight divided by height squared, $\left.\mathrm{kg} / \mathrm{m}^{2}\right)$. 
Physical fitness

Physical fitness was assessed from the Eurofit and FitnessGram battery. The test battery assesses cardiorespiratory fitness, muscular endurance, flexibility, and speed/agility. Flexibility and speed/agility tests were performed twice and the best score was recorded. Cardiorespiratory fitness and muscular endurance tests were measured one time because they are exhausting and require considerable time to administer. Physical education teachers who had undergone special training to correctly administer tests performed all physical fitness tests.

\section{Cardiorespiratory fitness}

Cardiorespiratory fitness was assessed with a 20 meter shuttle run test (Leger et al., 1988). Subjects were required to run between two lines $20 \mathrm{~m}$ apart, while keeping pace with audio signals from a pre-recorded CD. The initial speed was 8.5 $\mathrm{km} \cdot \mathrm{h}^{-1}$, which was increased by $0.5 \mathrm{~km} \cdot \mathrm{h}^{-1} \cdot \mathrm{min}^{-1}$ (1 min equals one stage). Subjects were instructed to run in a straight line, to pivot on completing a shuttle, and to pace themselves in accordance with the audio signals. The test was terminated when the subject failed to reach the end lines concurrent with the audio signals on two consecutive occasions or if the subject stops because of fatigue. All measurements were carried out under standardized conditions on an indoor rubber-floored gymnasium. Subjects were encouraged to keep running throughout the test. The last completed stage or half-stage was recorded for use in a formula to obtain $\mathrm{VO}_{2 \max }$ easily and quickly (Leger et al., 1988). 
Muscular endurance was assessed by the curl ups test (Castro-Pinero et al., 2009). The subject lies in a supine position on the mat, knees bent at an angle of approximately $90^{\circ}$, feet flat on the floor, legs slightly apart, arms behind the head. From this starting position, the subject curls up slowly, leading the elbows up to the knees and returns to the starting position completing as many repetitions as possible with a cadence of 1 curl every 3 seconds. The heels must maintain contact with the mat, and the elbows must touch the knees during the flexion movement and touch the mat during the extension movement. The test is terminated when the subject is not able to maintain the cadence, or to complete the flexion-extension movement correctly. Subjects were encouraged to breathe easily during the test.

\section{Speed}

The 50-meter sprint test was used to assess speed (Castro-Pinero et al., 2010). The subjects stood still in a comfortable position, feet behind the starting line, with no rocking movements. The test began on the whistle and was concluded when the runner crossed the finish line.

\section{Flexibility}

Flexibility was assessed by the back-saver sit and reach test (Ortega et al., 2011). The subject flexes the trunk and reaches forward as far as possible from a seated position, with one leg straight and the other bent at the knee. The test is performed once again with the opposite leg. The farthest position of the bar reached by each leg was scored in centimetres and the average of the distances reached by both legs was used in the analysis. 


\section{Speed/Agility}

Speed and agility were assessed using the $5 \times 10$ m shuttle run test (Council of Europe, 1983). Two parallel lines were drawn on the floor $5 \mathrm{~m}$ apart. The subject was instructed to run as fast as possible from the starting line to the second line and returns, crossing each line with at least one feet every time. The test was performed twice, covering a distance of $50 \mathrm{~m}(10 \times 5 \mathrm{~m})$. The stopwatch was stopped when the subject crosses the end line with one foot.

\section{Characteristics data}

Nutritional status was assessed using international age- and gender specific cutoff points (Cole et al., 2000). Socioeconomic status was assessed by the Human Development Index (HDI), developed by the United Nations Development Program (http://hdr.undp.org/en). The HDI combines three dimensions: (i) A long and healthy life: Life expectancy at birth; (ii) Education index: Mean years of schooling and Expected years of schooling; (iii) A decent standard of living: Gross National Income per capita. Low and high socio-economic status were determined using the thresholds of 0.5 (http://hdr.undp.org/en).

\section{Cardiovascular Risk}

Cardiovascular risk was categorized by sex-specific cut-offs for a healthy cardiorespiratory fitness level in adolescents proposed by FITNESSGRAM (Cureton \& Warren, 1990; The Cooper Institute, 2004). These cut-off points were extrapolated from the thresholds for adult population related with a higher risk of morbidity and mortality stablished by Blair et al. (1989). In addition, they recently showed to be 
valid for discriminating between adolescents with a more favourable cardiovascular profile and those with a less favourable profile (Lobelo et al., 2009).

\section{Statistical analysis}

The data were analysed using the Statistical Package for the Social Sciences, Windows v. 11.5 (SPSS Inc., Chicago, IL) and Excel 2003 (Microsoft Inc., Redmond, WA). Data are expressed as mean (standard deviation).

Independent t-tests were used to compare differences between different genders, BMI categories and levels of cardiovascular risk. To assess the relationship between BMI, HDI and the different components of physical fitness, Spearman's rho correlation coefficients were calculated.

A $P$ value of 0.05 was chosen for significance.

\section{Results}

Physical characteristics of subjects according to gender are presented in Table 1. One thousand eight hundred fifty-one volunteers, 946 male and 905 female, participated in the study. Mean age was $12.3 \pm 3.6$ years. The mean of height and weight were $1.54 \pm 0.8 \mathrm{~m}$ and $45.9 \pm 10.6 \mathrm{~kg}$, respectively. Among the subjects sample, $14 \%$ were overweight (17\% and $11 \%$ for boys and girls, respectively) and $4 \%$ were obese ( 5 and $2 \%$ for boys and girls, respectively).

Fitness results according to genders are presented in Table 2. Generally, boys performed better than girls. Significant differences were found between boys and girls in speed and cardiorespiratory fitness tests (Table 2). 
Fitness results according to BMI categories are presented in Table 3. Normal weight subjects had significantly better results than those who were overweight or obese for each physical fitness component $(\mathrm{p}<0.05)$.

Fitness results according to socioeconomics status are presented in Table 4. Subjects of high socioeconomic status performed significantly better than those of low socioeconomic status in speed/agility and cardiorespiratory fitness tests ( $\mathrm{p}$ $<0.05)$.

Correlations between BMI, socioeconomic status and physical fitness are provided in Table 5. Negative correlations were found between BMI and speed ( $r=-$ 0.134, $\mathrm{p}=0.001)$, speed/agility $(\mathrm{r}=-0.089, \mathrm{p}=0.001)$, muscular endurance $(\mathrm{r}=-$ 0.087, $\mathrm{p}=0.001)$ and cardiorespiratory fitness test $(\mathrm{r}=-0.204, \mathrm{p}=0.001)$. Positive correlations were found between socioeconomic status and speed $(\mathrm{r}=0.640, \mathrm{p}=$ $0.004)$, speed/agility $(\mathrm{r}=0.243, \mathrm{p}=0.001)$, muscular endurance $(\mathrm{r}=0.179, \mathrm{p}=$ $0.001)$, flexibility $(\mathrm{r}=0.590, \mathrm{p}=0.009)$ and cardiorespiratory fitness $(\mathrm{r}=0.510, \mathrm{p}=$ $0.022)$.

\section{Cardiovascular Risk}

The percentage of French schoolchildren at future risk of cardiovascular disease is presented in Figure 1. The percentage of subjects with low cardiorespiratory fitness and increased cardiovascular risk was higher in boys than girls. In general, subjects at increased cardiovascular risk performed more poorly on physical fitness tests than those not at risk (Figure 2) $(\mathrm{p}<0.05)$.

\section{Discussion}


Physical fitness in childhood and adolescence is a potent predictor of health, not only over the further years but also at the adult age (Ortega et al., 2008). Cardiorespiratory fitness but also muscular fitness have been increasingly recognized in the prevention of chronic disease and inversely associated with established and emerging cardiovascular risk factors in adolescents (Wolfe, 2006; Benson et al., 2006; Steene-Johannessen et al., 2009; Magnussen et al., 2012). The purpose of this study was to measure physical fitness in a large sample of French schoolchildren in the Region of Ile de France, to compare our findings with other European countries, and, based on the measurement of fitness in the present sample, to estimate the percentage of adolescents at increased cardiovascular risk.

Our findings, that adolescent boys are physically fitter than adolescent girls, agrees with previous studies assessing health-related physical fitness (Ortega et al., 2011; Ortega et al., 2005; Secchi et al., 2014). Our results, that adolescents of higher socio economic status are more physically fit than adolescents of low socio economic status, also agrees with previous findings which showed a significant difference between socioeconomic groups in aerobic fitness of female high school students (Fahlman et al., 2006; Welk et al., 2010). Authors examined the relationship between demographic and geographic variability in aggregated school-level data on aerobic fitness and concluded that school-level attainment of fitness was consistently higher in schools categorized as high socioeconomic status (Welk et al., 2010).

Findings of the present study showed that physical fitness of French schoolchildren living in the Ile de France region was lower compared to European norms. European normative values are available for the cardiorespiratory fitness, speed and flexibility tests (Ortega et al., 2011; Castro-Pinero et al., 2009; CastroPinero et al., 2010). Compared to European adolescent boys our male subjects were 
at the $50^{\text {th }}$ percentile while adolescent girls were well below the European mean, i.e., $20^{\text {th }}$ to $30^{\text {th }}$ percentile for the flexibility (Ortega et al., 2011). For the cardiorespiratory fitness, French adolescent boys from our study were slightly above the European mean in cardiorespiratory fitness, between the $50^{\text {th }}$ and $70^{\text {th }}$ percentiles while our adolescent girls were at the $40^{\text {th }}$ percentile of the European mean (Ortega et al., 2011). Results from the 50 meter sprint test showed that our subjects, both boys and girls, performed poorly compared to Spanish adolescents, falling between the $20^{\text {th }}$ and $30^{\text {th }}$ percentile for boys and the $30^{\text {th }}$ and $40^{\text {th }}$ percentile for girls (CastroPinero et al., 2010). Our findings concur with studies of physical fitness levels in children and adolescents of different European countries, which showed that French adolescents were classified relatively poorly, $14^{\text {th }}$ of 22 countries (Tomkinson et al., 2007).

To our knowledge, no data are available assessing cardiorespiratory fitness and cardiovascular risk in French adolescents. Using cardiorespiratory thresholds associated with increased cardiovascular risk, we estimated the percentage of adolescent boys and girls at cardiovascular risk in adulthood as $15.3 \%$ and $10.2 \%$ (The Cooper Institute for Aerobics research, 2004). Thresholds fixed to discriminate no risk or future cardiovascular risk are 42 and $38 \mathrm{ml} \cdot \mathrm{kg}^{-1} \cdot \mathrm{min}^{-1}$ for adolescent boys and girls, respectively. Based on these thresholds more than one in ten French adolescents are at risk to develop cardiovascular disease in adulthood. Moreover, adolescents at risk for cardiovascular disease likely would be even greater when taking low results in other physical fitness tests, e.g. muscular endurance, speed, agility and flexibility into consideration. Cardiorespiratory, speed/agility and muscular fitness were all shown to be associated with established and emerging cardiovascular disease risk factors (Ortega et al., 2008). Physical fitness in childhood 
and adolescence is a powerful marker of health (Ortega et al., 2008). Based on findings from the present study, the authors recommend promoting school-based intervention programs for this age group that increase vigorous physical activity and improve physical fitness. Furthermore, it was observed that health-related fitness testing required minimal time and equipment, was easily administered by a physical education teacher, was safe, inexpensive, and easily adapted according to age.

In summary, physical fitness in adolescents' girls living in the Ile de France region is generally low when compared with existing European values. In contrast, the adolescents' boys are generally fitter and also above the average of the European data. Low physical fitness levels were related to obesity and low socioeconomic status. Implementing a physical education curriculum to promote positive health related physical fitness in the schools of the region would help to promote better health and fitness.

\section{Acknowledgements}

The authors thank all participating adolescents and teachers for their collaboration in the study.

\section{Conflict of Interest statement}

The authors declared no conflict of interest. 


\section{References}

Béghin L, Castera M, Manios Y, Gilbert CC, Kersting M, De Henauw S, Kafatos A, Gottrand F, Molnar D, Sjöström M, Leclercq C, Widhalm K, Mesana MI, Moreno LA, Libersa C. Quality assurance of ethical issues and regulatory aspects relating to good clinical practices in the HELENA Cross-Sectional Study. Int J Obes (2008), 32: S12-S12.

Benson AC, Torode ME, Singh MA. Muscular strength and cardiorespiratory fitness is associated with higher insulin sensitivity in children and adolescents. Int J Pediatr Obes (2006); 1: 222-231.

Blair SN, Kohl HW, 3rd, Paffenbarger RS, Jr., Clark DG, Cooper KH, Gibbons LW. Physical fitness and all-cause mortality. A prospective study of healthy men and women. JAMA (1989); 262: 2395-401.

Castro-Piñero J, González-Montesinos JL, Keating XD, Mora J, Sjöström M, Ruiz JR. Percentile values for running sprint field tests in children ages 6-17 years: influence of weight status. Res Q Exerc Sport (2010); 81: 143-51.

Castro-Piñero J, González-Montesinos JL, Mora J, Keating XD, Girela-Rejón MJ, Sjöström M, Ruiz JR. Percentile values for muscular strength field tests in children aged 6 to 17 years: influence of weight status. J Strength Cond Res (2009); 23: 2295-2310.

Cole TJ, Bellizzi MC, Flegal KM, Dietz WH. Establishing a standard definition for child overweight and obesity worldwide: international survey. BMJ (2000); 320: 1240-1243. 
Council of Europe. Testing physical fitness EUROFIT experimental battery: provisional handbook. 1983: Strasbourg: The Council.

Cureton KJ, Warren GL. Criterion-referenced standards for youth health-related fitness tests: a tutorial. Res Q Exerc Sport (1990); 61: 7-19.

Fahlman MM, Hall HL, Lock R. Ethnic and socioeconomic comparisons of fitness, activity levels, and barriers to exercise in high school females. J Sch Health (2006); 76: 12-17.

Gale CR, Martyn CN, Cooper C, Sayer AA. Grip strength, body composition, and mortality. Int J Epidemiol (2007), 36: 228-235.

Harriss DJ, Atkinson G. Update-Ethical standards in sport and exercise science research. Int J Sports Med (2011); 32: 819-821.

Heyward VH. Advanced fitness assessment and exercise prescription. In: 3e édition. Champain, Illinois, Human Kinetics Books, 1991

Leger LA, Mercier D, Gadoury C, Lambert J. The multistage 20 metre shuttle run test for aerobic fitness. J Sports Sci (1988); 6: 93-101.

Lobelo F, Pate RR, Dowda M, Liese AD, Ruiz JR. Validity of cardiorespiratory fitness criterion-referenced standards for adolescents. Med Sci Sports Exer (2009); 41: 1222-9. 
Magnussen CG, Schmidt MD, Dwyer T, Venn A. Muscular fitness and clustered cardiovascular disease risk in Australian youth. Eur J Appl Physiol (2012); 112: 31673171.

Malina RM, Eisenmann JC, Cumming SP, Ribeiro B, Aroso J. Maturity-associated variation in the growth and functional capacities of youth football (soccer) players 13-15 years. Eur J Appl Physiol (2004); 91: 555-562.

Myers J, Prakash M, Froelicher V, Do D, Partington S, Atwood JE. Exercise capacity and mortality among men referred for exercise testing. N Engl J Med (2002); 346: 793-801.

Olds T, Tomkinson G, Léger L, Cazorla G. Worldwide variation in the performance of children and adolescents: an analysis of 109 studies of the 20-m shuttle run test in 37 countries. J Sports Sci (2006); 24: 1025-1038.

Ortega FB, Artero EG, Ruiz JR, España-Romero V, Jiménez-Pavón D, Vicente-Rodriguez G, Moreno LA, Manios Y, Béghin L, Ottevaere C, Ciarapica D, Sarri K, Dietrich S, Blair SN, Kersting M, Molnar D, González-Gross M, Gutiérrez A, Sjöström M, Castillo MJ. Physical fitness levels among European adolescents: the HELENA study. Br J Sports Med (2011); 45: 20-29.

Ortega FB, Ruiz JR, Castillo MJ, Moreno LA, González-Gross M, Wärnberg J, Gutiérrez A. Low level of physical fitness in Spanish adolescents. Relevance for future cardiovascular health (AVENA study). Rev Esp Cardiol (2005); 58: 898-909. 
Ortega FB, Ruiz JR, Castillo MJ, Sjostrom M. Physical fitness in childhood and adolescence: a powerful marker of health. Int J Obes (2008); 32: 1-11.

Ruiz JR, Castro-Piñero J, Artero EG, Ortega FB, Sjöström M, Suni J, Castillo MJ. Predictive validity of health-related fitness in youth: a systematic review. Br J Sports Med (2009); 43: 909-923.

Secchi JD, García GC, España-Romero V, Castro-Piñero J. Physical fitness and future cardiovascular risk in argentine children and adolescents: an introduction to the ALPHA test battery. Arch Argent Pediatr (2014); 112: 132-140.

Sjolie AN. Low-back pain in adolescents is associated with poor hip mobility and high body mass index. Scand J Med Sci Sports (2004); 14: 168-175.

Steene-Johannessen J, Anderssen SA, Kolle E, Andersen LB. Low muscle fitness is associated with metabolic risk in youth. Med Sci Sports Exerc (2009); 41: 1361- 1367.

The Cooper Institute. FITNESSGRAM test administration manual. Champaign: Human Kinetics; 2004.

Tomkinson GR, Olds TS, Borms J. Who are the Eurofittest? Med Sport Sci (2007), 50:10428. 
Vicente-Rodriguez G, Dorado C, Perez-Gomez J, Gonzalez-Henriquez JJ, Calbet JA. Enhanced bone mass and physical fitness in young female handball players. Bone (2004); 35: $1208-1215$.

Vicente-Rodríguez G, Urzanqui A, Mesana MI, Ortega FB, Ruiz JR, Ezquerra J, Casajús JA, Blay G, Blay VA, Gonzalez-Gross M, Moreno LA. Physical fitness effect on bone mass is mediated by the independent association between lean mass and bone mass through adolescence: a cross-sectional study. J Bone Miner Metab (2008); 26: 288-294.

Welk GJ, Meredith MD, Ihmels M, Seeger C. Distribution of health-related physical fitness in Texas youth: a demographic and geographic analysis. Res $Q$ Exerc Sport (2010); 81: S6-15.

Wolfe RR. The underappreciated role of muscle in health and disease. Am J Clin Nutr (2006); 84: 475-482. 


\section{Legends}

Figure 1. Percentages of French adolescents with a cardiovascular risk associated with a low cardiorespiratory fitness (The Cooper Institute for Aerobics research, 2004).

Figure 2. Difference between the two groups (no and future cardiovascular risk) in adolescents for the different health-related physical fitness components. All tests were significantly different $(p<0.05)$ (The Cooper Institute for Aerobics research, 2004).

Table 1. Physical characteristics of subjects $(\mathrm{n}=1851)$

Table 2. Physical fitness results (mean \pm SD) according to gender

Table 3. Physical fitness results (mean \pm SD) according to BMI categories

Table 4. Physical fitness (mean \pm SD) according to socioeconomic status

Table 5. Spearman's rho correlations $(p)$ with BMI and HDI 
Table 1. Physical characteristics of subjects $(n=1851)$

\begin{tabular}{lccc}
\hline & Boys & Girls & All \\
\hline $\mathrm{N}$ & 946 & 905 & 1851 \\
Age $(y r)$ & $12.3 \pm 5$ & $12.4 \pm 0.9$ & $12.3 \pm 3.6$ \\
Height $(m)$ & $1.54 \pm 0.1$ & $1.54 \pm 0.1$ & $1.54 \pm 0.8$ \\
Weight $(k g)$ & $46.1 \pm 10.8$ & $45.9 \pm 10.4$ & $45.9 \pm 10.6$ \\
Overweight/Obese $(n)$ & $157 / 46$ & $102 / 23$ & $259 / 69$ \\
\hline
\end{tabular}


Table 2. Physical fitness results (mean $\pm \mathrm{SD}$ ) according to gender

\begin{tabular}{lcc}
\hline & Boys $(\mathrm{n}=946)$ & Girls $(\mathrm{n}=905)$ \\
\hline Speed $(\mathrm{sec})$ & $9.36 \pm 1.59$ & $9.58 \pm 1.98^{*}$ \\
Speed/Agility $(\mathrm{sec})$ & $19.96 \pm 3.1$ & $19.77 \pm 3.04$ \\
Muscular endurance $(\mathrm{n})$ & $32 \pm 19$ & $31 \pm 19$ \\
Flexibility $(\mathrm{cm})$ & $19.9 \pm 8.6$ & $19.8 \pm 8.6$ \\
Cardiorespiratory fitness $\left(\mathrm{VO}_{2} \mathrm{ml} . \mathrm{kg} \cdot \mathrm{min}^{-1}\right)$ & $49.7 \pm 7.3$ & $45.9 \pm 6.5^{*}$ \\
\hline
\end{tabular}

$* \mathrm{p}<0.05$ 
Table 3. Physical fitness results (mean \pm SD) according to BMI categories

\begin{tabular}{lcc}
\hline & $\begin{array}{c}\text { Normal Weight } \\
(\mathrm{n}=1523)\end{array}$ & $\begin{array}{c}\text { Overweight + Obese } \\
(\mathrm{n}=328)\end{array}$ \\
\hline Speed $(\mathrm{sec})$ & $8.32 \pm 1.62$ & $10.23 \pm 3.24^{*}$ \\
Speed/Agility $(\mathrm{sec})$ & $19.82 \pm 3.12$ & $22.24 \pm 4.01^{*}$ \\
Muscular endurance $(n)$ & $41 \pm 22$ & $18 \pm 7^{*}$ \\
Flexibility $(\mathrm{cm})$ & $24.8 \pm 7.6$ & $13.7 \pm 6.7^{*}$ \\
Cardiorespiratory fitness $\left(\mathrm{ml}^{*} \mathrm{~kg}_{\mathrm{min}} \mathrm{min}^{-1}\right)$ & $44.3 \pm 8.9$ & $25.6 \pm 6.9^{*}$ \\
\hline
\end{tabular}

$* \mathrm{p}<0.05$ 
Table 4. Physical fitness (mean \pm SD) according to socioeconomic status

\begin{tabular}{lcc}
\hline & Low & High \\
\hline Speed $(\mathrm{sec})$ & $9.51 \pm 1.64$ & $9.46 \pm 1.85$ \\
Speed/Agility $(\mathrm{sec})$ & $20.57 \pm 3.57$ & $19.61 \pm 2.81^{*}$ \\
Muscular endurance $(n)$ & $29 \pm 18$ & $32 \pm 19$ \\
Flexibility $(\mathrm{cm})$ & $19.6 \pm 8.8$ & $20.1 \pm 8.5$ \\
Cardiorespiratory fitness $\left(\mathrm{ml} \mathrm{kg} . \mathrm{min}^{-1}\right)$ & $38.1 \pm 6.2$ & $39.3 \pm 3.8^{*}$ \\
\hline
\end{tabular}

$* \mathrm{p}<0.05$ 
Table 5. Spearman's rho correlations $(p)$ with BMI and HDI

\begin{tabular}{lcc}
\hline & BMI & HDI \\
\hline Speed $(\mathrm{sec})$ & $-\mathbf{0 . 1 3 4}(\mathbf{0 . 0 0 1})$ & $\mathbf{0 . 6 4 0}(\mathbf{0 . 0 0 4})$ \\
Speed/Agility $(\mathrm{sec})$ & $\mathbf{- 0 . 0 8 9 ( \mathbf { 0 . 0 0 1 } )}$ & $\mathbf{0 . 2 4 3}(\mathbf{0 . 0 0 1})$ \\
Muscular endurance $(n)$ & $\mathbf{- 0 . 0 8 7 ( \mathbf { 0 . 0 0 1 } )}$ & $\mathbf{0 . 1 7 9}(\mathbf{0 . 0 0 1})$ \\
Flexibility $(\mathrm{cm})$ & $-0.005(0.842)$ & $\mathbf{0 . 5 9 0}(\mathbf{0 . 0 0 9})$ \\
Cardiorespiratory fitness $\left(\mathrm{ml}^{\left.\mathrm{kg} . \mathrm{min}^{-1}\right)}\right.$ & $\mathbf{- 0 . 2 0 4 ( \mathbf { 0 . 0 0 1 } )}$ & $\mathbf{0 . 5 1 0}(\mathbf{0 . 0 2 2})$ \\
\hline
\end{tabular}




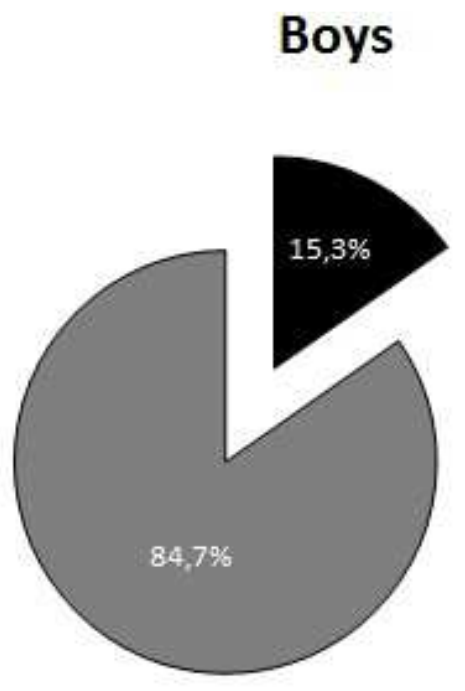

\section{Girls}

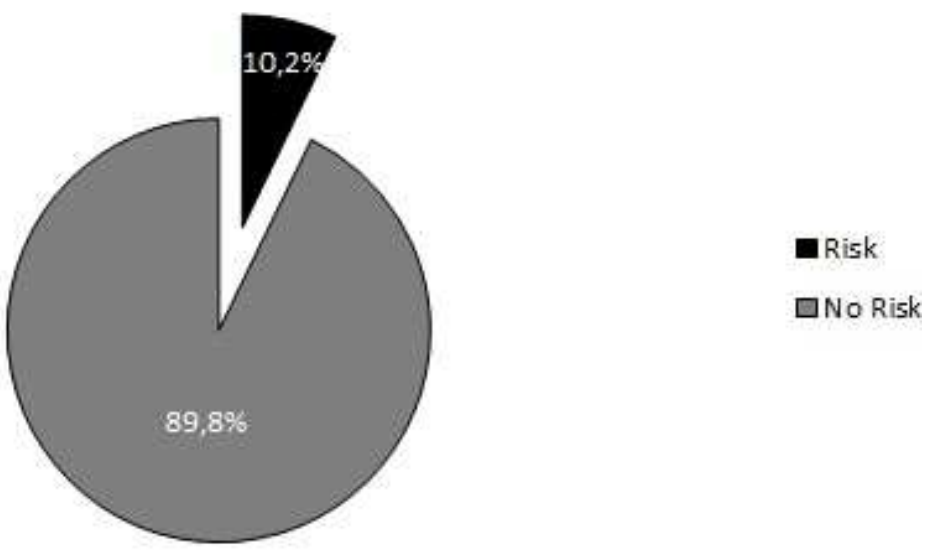

Figure 1. Percentages of French adolescents with a cardiovascular risk associated with a low cardiorespiratory fitness (The Cooper Institute for Aerobics research, 2004). 


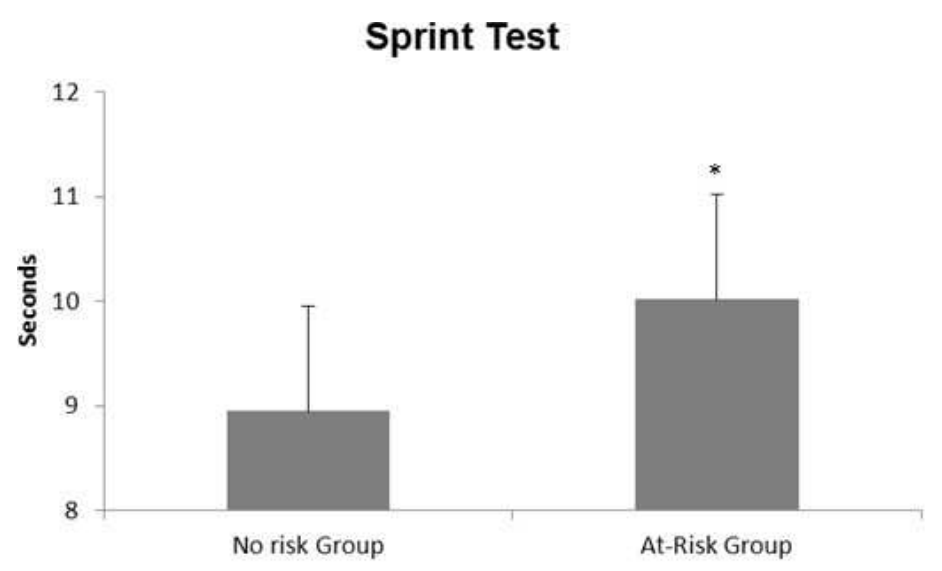

Muscular Endurance Test

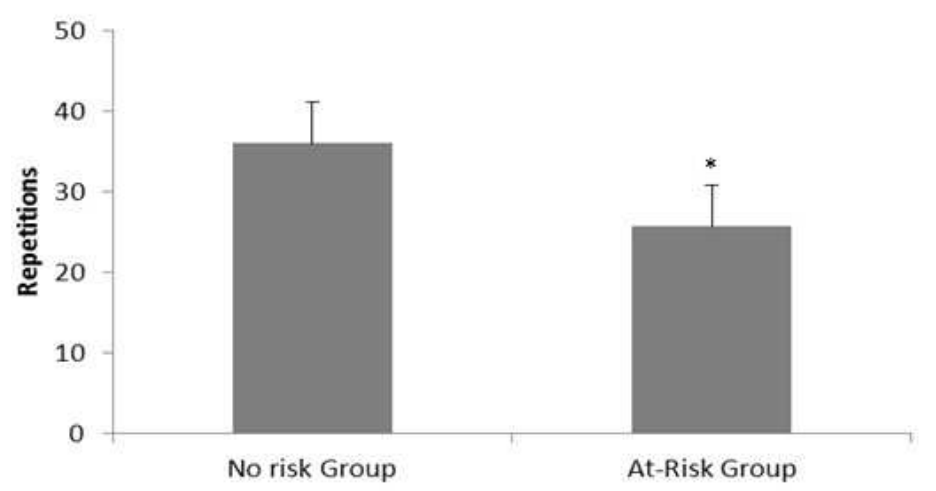

Speed/Agility Test

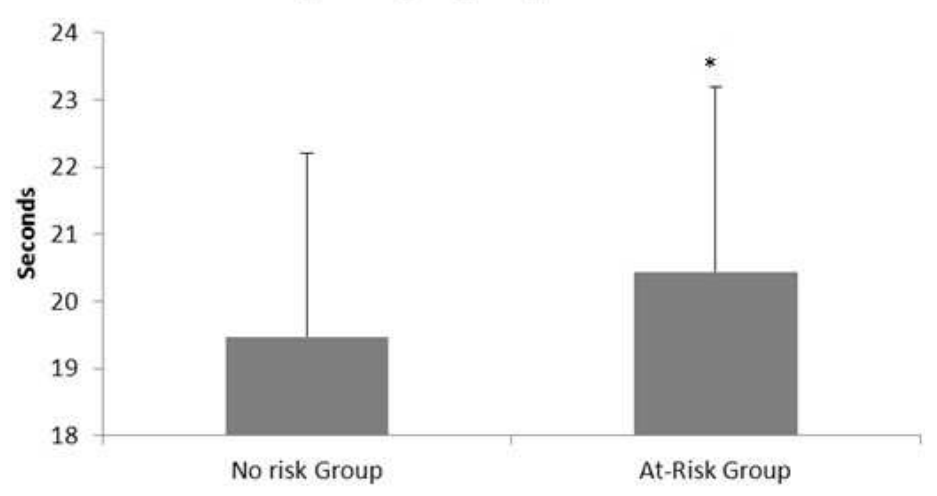

Flexibility Test

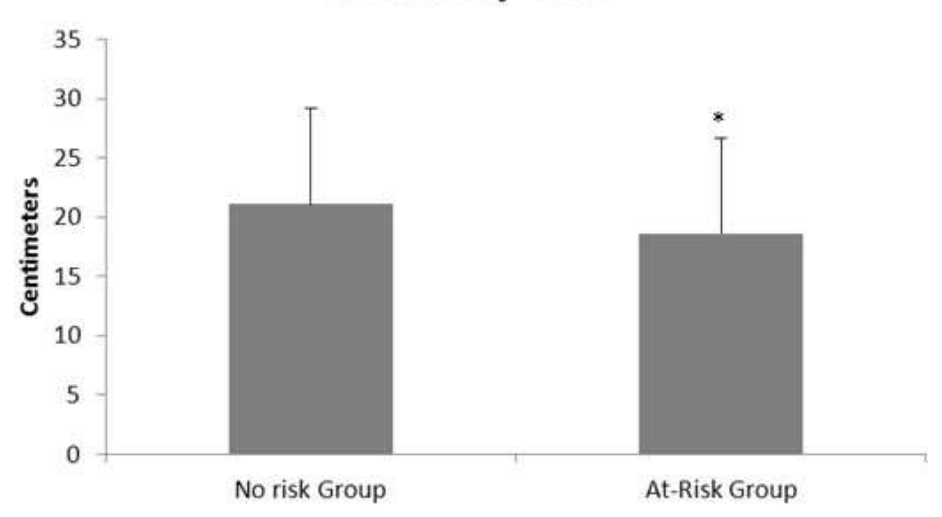

Figure 2. Difference between the two groups (no and future cardiovascular risk) in adolescents for the different health-related physical fitness components. All tests were significantly different $(p<0.05)$ (The Cooper Institute for Aerobics research, 2004). 